\title{
Correction to: A Critique of Barbieri's Code Biology Through Rosen's Relational Biology: Reconciling Barbieri's Biosemiotics with Peircean Biosemiotics
}

\section{Federico Vega ${ }^{1}$}

Published online: 22 August 2018

(c) Konrad Lorenz Institute for Evolution and Cognition Research 2018

\section{Correction to: Biological Theory}

https://doi.org/10.1007/s13752-018-0302-1

In the 'Barbieri's Concept of Mechanisms' section on page 12 of above mentioned article the text erroneously reads 'Rosen, quoting Alberts et al. (2007), highlights...' The correct text should read 'Barbieri, quoting Alberts et al. (2007), highlights...'.

The original article has been corrected. 